\title{
Summer does not spell greenhouse
}

\section{General curiosity about climatic change is usually provoked by cold winters or hot summers. But speculation is too little constrained by statistics.}

IN spite of the attention that has recently been paid to the possible effects of carbon dioxide on the climate, and to anthropogenic influences more generally, this summer has once again confirmed that the most powerful anthropogenic influence on climate as a topic of conversation remains what it has always been - the blend of curiosity and incredulity that makes each annual seasonal alternation a cause of public astonishment tinged with suspicion that the world is about to come to an end.

In parts of Britain and North America, for example, the occurrence during the past few weeks of consecutive days of higher than usual temperatures has triggered off a string of unruly speculations. The opinion that dust from last year's Mexican volcano El Chichón must be responsible for this year's good summer is often held in Britain. Fortunately there has so far been only meagre speculation that the cause may be the even more distant behaviour of the El Nino current in the Pacific. For if fluctuations of this current can profoundly affect the weather in the southwestern Pacific up to six months later, may they not also explain why enthusiasts for the British sport of cricket are this year complaining not that it is too wet to play the game but that the grass surfaces are too hard? And atmospheric carbon dioxide is also an obvious explanation.

What follows is a simple and oldfashioned statement of the reasons why none of these explanations is necessary (which implies that it is irrelevant to this year's weather whether one or more of them may be sufficient). The statistical traps in telling what to make of one warm summer are familiar but nevertheless are generally overlooked. Especially in places such as Britain, the mean temperature for, say, July may vary from one year to the next by as much as $5^{\circ}$ centigrade. At any one location, evidence of climatic trends is well buried in such noise (but less deeply on the eastern seaboard of North America than in Western Europe). Thus data compiled by J. de Vriess (University of California, Berkeley) for the mean winter temperature (December, January and February) in the Netherlands show a standard deviation of $1.98^{\circ}$ centigrade on a mean of $2.16^{\circ}$, between 1945 and 1975 , which no doubt explains why the canals are not always safe for skating.

In these frustrating circumstances, those looking for trends tend to fall back on running means (5 or 10 year averages of monthly mean temperature, for example). One snag is that too short a period will leave too much noise but too long a period will obscure a trend. British amateur climatologists should here again be warned that Britain is almost the worst place to look for trends. H.H. Lamb (in his monumental Climate: Past, Present and Future, Vol. 2, Methuen, 1977) has compiled 40-year running means of mean July temperature at various places during the past century. The data show that at Toronto, the temperature increased by $1.5^{\circ}$ centigrade between 1840 and 1960 , but the corresponding figures for Britain show no trend at all but only fluctuations. It is ironical (but probably not accidental) that Britain should be so well endowed with curiosity about climatic change yet so poorly placed to tell the signal from the noise.

Despair about climatic noise has led to other stratagems - in particular, to the search for some climatically related phenomenon that might prove to be a sensitive indicator of underlying trends. Thus Lamb (op. cit.) has lovingly collected data indicative of hot summers in central England (defined as a mean temperature of $16^{\circ}$ centigrade or more in June, July and August). His chief finding is that there are never more than four of these in a decade (in the 1770 s, 1800 s and 1830 s). Since the restoration of the Stuarts in 1660 , there have been two decades with no hot summers, eight with one, ten with two and seven with three. This distribution is more peaked around the mean than a Poisson distribution, but not significantly so. The obvious difficulty is that these warm summers do not fit well with what little is known of global trends - the summer of 1976 , the warmest in Britain since 1862 , occurred in a cool year for the Northern Hemisphere as a whole.

The moral is that to attempt to identify global trends in climate from records of a simple variable at a single place is like trying to assess the state of the world's economy from the price of caviar at a local supermarket. For one thing, what happens at one place may be negated by what happens elsewhere. Thus Lamb records that cold winters in Britain appear to have been winters in which Lake Suwa in Japan remained unfrozen and vice versa.

Swings and roundabouts are thus one obvious source of the annual fluctuations that occupy climatologists. And the heat capacity of the troposphere is only one way in which solar energy may be stored. The dynamical energy of the atmosphere (including its distribution of mass with altitude) and the energy associated with its chemical composition (the evaporation of water for example) must be in fluctuating equilibrium with sheer atmospheric enthalpy, while energy also flows in each direction between the oceans and the atmosphere. Trend-spotters should more zealously consider all these causes of fluctuation before claiming success.

In all the circumstances, it is simple good luck that there has been some success in picking out a few significant climatic trends. Thus it seems, on the basis of temperatures averaged over longitude, that there was a marked warming trend between 1910 and about 1940, followed by a significant cooling in the succeeding 30 years (see Wigley, T.M.L. and Jones, P.D. Nature 292, 205; 1981). These recent trends, however, are far from comforting for the carbon dioxide lobby. The early warming trend had the sign expected of the greenhouse effect, but was much larger than predicted for the 14 per cent increase of carbon dioxide concentration between 1900 and 1940 (although there is some evidence that the equilibrium concentration may have been less than generally assumed, perhaps only 260-270 parts per million). The cooling trend thereafter is, however, frankly inconsistent with the greenhouse model. This is why Wigley and Jones concluded, two years ago, that even if a warming trend due to carbon dioxide has set in since 1970, it will be necessary to wait for a period comparable with that of the early warming trend before being certain what is afoot. Obviously the problem would be simplified if something were known of the causes of these earlier fluctuations. The moral, for those who would demonstrate the reality of the greenhouse effect, is to pay more attention to the other causes of lowfrequency climatic variation.

This does not imply that the calculations of the greenhouse effect so far carried out are to be taken at their face value. While only a half of the carbon dioxide released apparently accumulates in the troposphere, doubts must persist about what happens to the rest. Similarly, too little is known of the exchange of heat (or even carbon dioxide) between the atmosphere and the oceans, while most of the numerical climate models so far do not allow for real clouds, or for the patchiness of the Earth's albedo.
John Maddox 